\title{
Commonwealth In Uzbek And World Literature
}

\author{
Nilufar Sultonova ${ }^{a}$ \\ ${ }^{a}$ Doctor of Philosophy in Philology,Karshi State University
}

Article History: Received: 10 November 2020; Revised 12 January 2021 Accepted: 27 January 2021; Published online: 5 April 2021

\begin{abstract}
This article analyzes the artistic criteria of modification through its literary works. The commonality of Uzbek and world literature, as well as the individual style of the writers, the system of images he created, reflected the process of
\end{abstract} expressing the reality of a talented scientist, the delicate human feelings in his heart.

Keywords: Modus, attribute, modification, criterion, mythology, image modification, narration, epic thinking, folk composition, measurement

\section{Introduction}

Modification is the oldest Latin word, which is defined in the book "Poetic Dictionary of Kvyatkovskogo" as follows: , perform), rebuild, change shape with the acquisition of something new. It is clear that the concept of modification underlies the philosophical views of the philosopher Spinoza on the popular substance and modus. The Philosophical Dictionary states: "Modus means measure, criterion, method, way, method, style. Represents the property of an object in certain situations. It differs from the attribute in this respect. According to Spinoza, modus is a means of representing all transient (migratory) states of a substance. Its existence depends not on itself, but on the substance and its properties. In mode, the quality of mobility and mobility of what finds its origin in a single, eternal, boundless material subtension is reflected."

Hence, the mode has the property of variability. This, in turn, ensures constant changes in material and spiritual processes, resulting in the emergence of new models. The phenomenon of modification in itself applies to both literary and historical processes. The formation of epic genres other than those that exist in the whole case, such as the folk heroic epic, has been noted in some studies as being reborn in a changed form.

In the study of MA Alekseeva "Modification of poetic mythologies of the XIX century in the works of B. Pasternak in the 1910s" it is said that the phenomenon of modification is a manifestation of artistic traditions. The scholar says: "Attitudes towards tradition are negative and positive; can be understood and not understood ... The poet struggles with chaos and presents harmony to the world. It is a mythology that is common to all cultures and differs in its various forms. "Speaking about the processes of artistic modification of a number of mefologems in B.Pasternak's poetry, the scientist compares them with the mythologues in the poetry of M.Yu. Lermontov, E.A. Baratynsky, F.I. proves.

M. Alekseeva's conclusion further clarifies our views on artistic modification: "Mythologisms mastered in the works of the 1910s are modified by the dynamic style of B. Pasternak. Clinging to its poetic system reveals the complex, dialogical way of thinking of the twentieth century.

Hence, the modification of artistic components is directly related to some artistic tradition. The literary needs of the period, the creative level of the author, the artistic laboratory, the modification according to the ideological purpose can be manifested in the intersection of various poetic components. Or it is possible that this process will occur on a large scale, within the framework of not one, but several artistic components.

AR Borova's research "Image modification: A. Keshakova's poetry of the 1960s" directly deals with image modification. If M.Alekseeva speaks about the modification of mythological phrases and scientifically substantiates that this phenomenon took place within the traditions of one national literature (Russian literature), A.Borova thinks that the image modification takes place within the artistic traditions of literary relations between the two nations. "The fact that the integration of poetic ideas in the layer of thinking takes place in the layers of thinking at the cognitive-rational level belongs to a relatively new era of intercultural relations. Writes the scientist. - This aspect is manifested in a broad, detailed situation, especially in the areas of cultural relations between the North Caucasus and Russia. For these and similar reasons, the burbut-compatible forms and 
complexes of associativity show that the virtual objects associated with them have consistently influenced the mountain world of Russian artistic thought. ”

According to A. Borov, the modified appearance of the literary influence does not occur in the form of large scale canvases, but in the inner specific layers of artistic interpretation. The internal laws of modification, which differ from syncretization, synthesis and other forms of literary influence, are manifested in the peculiarities of its purely poetic, psychological, creative laboratory. The artist's purely creative-individual approach to a particular period of contemporary (eg, Russian) literature, certain poetic methods, artistic styles is the impetus for the beginning of the modification process. "The personal freedom of the creator is such an absolute foundation that it can undoubtedly change the world," the scientist wrote.

At the same time, social events, social, political, economic and psychological changes in the life of society are also important for the occurrence of modification processes. Speaking about the poetry of the KabardinoBalkarian poet A. Keshkov in the 60s of the last century, A. Borova emphasizes the period of "shapada" (ottepl), which is characteristic of all the former Soviet republics. During the period of relative freedom, all Soviet writers, poets and playwrights were divided into two camps, one for the deepening of social realism, the other for the concept of personal freedom and free creativity, Keshkov chose the second way and did the right thing. Such a correct choice is a positive development in the works of A. Keshkov, which, in the tradition of Russian "silver age" poetry, led the creative thinking of the Kabardino-Balkarian people to their individual artistic world. "For A. Keshkov," writes A. Borova, "the problem of national style, the peculiarity of Kabardian poetry, was a purely personal problem." There is no doubt that he shaped the path of development of his work with a clear purpose.

It follows that the modification processes inherent in the national literature can occur dynamically in any social context. For a complete artistic modification, it is important that three factors work together: literary traditions on a global or narrow scale (eg, the Soviet Union), the national language and literature, in particular, the individual creative personality of the artist, the artistic idea. Only then does fiction enter the period of enriching its territory with new, national and modified images that combine the creative personality of the national poet.

J.A. Burtseva's study "Modification of genre forms" discusses modern prose, the role and significance of the phenomenon of modification in its renewal. At the same time, the scientist takes the author's individual approach as the main criterion in inter-genre modification. The author emphasizes individuality in the change of genre canons and the emergence of non-canonized genres. The genre-changing role of folk legends in the prose of Russian-speaking ruby writers is analyzed. It can be concluded from this that national folklore can also be a factor in the modification of genres in modern literature. The narrative form of national folk prose directly serves as a renewal of epic thinking, the style of work, the active modification of images.

The following thoughts of the Russian scientist N.Aleksanrdov emphasize the legitimacy of modification processes in modern prose, but also emphasize that the topic of our dissertation is determined by today's aesthetic innovations in Uzbek literature: "Today, the genre has survived as an aesthetic reflection of the subject.That is, the memory of the genre remains, and now it is possible to return to the form of a restrictive genre only through stylization with a line on it. Indeed, this situation is typical of today's Uzbek prose.

G. Binova's research "Genre modification in the latest Russian prose" has a methodological significance, as it focuses directly on the interpretation of prose genres.

He argues that one of the leading features of Russian modern prose is the distortion of the canons of the genre, that such distortion occurs as a result of modification operations. The departure of fiction from the canons of genre to purely individual interpretation is a characteristic feature of the modern Russian literary process. remained. This shows that the historically formed genre criteria have been replaced by a real anarchy based on rules. ”

According to the literary critic, the era of classical novels, which to some extent defined the canons of $\mathrm{M}$. Bakhtin, has passed, with the change of traditional criteria of the XIX - XX centuries, dominated by great social events, political struggles, cultures that formed a complex of rules of morality. The "unspent potentials" in the novel of L. Tolstoy, F. Dostoevsky, the spirit of striving for the future does not exist today. In Russian novels, this process ended with Grossman's Life and Destiny and Solzhenitsyn's Gulag Archipelago.

It is possible to fully agree with these views of the researcher. This process has been going on not only in Russian literature, but also in English, French, German, and Latin American novels since the late twentieth and early twenty-first centuries. This is evidenced by Paulo Coelho's novels Al Alchemist, which has been translated into Uzbek three times, or 13 Minutes, Shestaya Gora, published in Russian, and Jenny Erpenbek's Istab Makon, translated by H. Kochkarova.

"Thus," G. Binova continues, "the model of the modern Russian novel has changed. Writing a classic novel "did not look like", prose again and again took the form of essays, pamphlets, confessions. Because the writer 
wanted to understand the "movement of history" ... Philosophy began to strive for a clear language of the exact sciences. After that, of course, some of the problems of philosophy passed into the literature.As a result, the essay, which lives on the border of literature and philosophy, has become a relatively flexible form. "Now the novel is being written not by "suffering" authors, but by scholars who have acquired an analysis of reality. Thus, the psychological and social changes that took place in the personality and purpose of the person became a factor that led to the modification of the novel form. The essence of the modified eccentric novels is not the plot movement, but the relatively weakened, far-fetched plot of the author's thinking.

G. Binva observed that the fact that the essayization of the classical novel genre led to its hybridization with philosophy was a manifestation of a modification characteristic of Russian novels, while another manifested it in the form of "inferior literature." The novel moved away from the task of serving the great literature or literary elite to serve the culture of the masses. The following thoughts of the Russian writer A.Kurchatkin serve to emphasize once again that such a change in the modern novel is a real social, cultural, psychological phenomenon: "The great literary era for Russian society is over. The era of low literature has begun. '

Literary critic K. Yuldashev said: "The convergence of high art and disposable mass culture, first of all, with the spread of understanding as a hedonistic (pleasure) tool that should serve to entertain and relax, people can have different levels of artistic taste, and this The preconceived notion that the root is rooted in a person's intellect and emotions, as well as in the social and living conditions in which he lives, loses its value, "said A. Kurchatkin as a logical continuation of his thoughts. This conclusion, which is the result of studying the latest examples of Uzbek and world literature, is true, no matter how cruel it may sound, as it applies to today's Uzbek prose.

Of course, in such works the question of art and literary language, which is the most important condition of literature, falls to the last level. In such marketable "works", the elements of art and artistic language inevitably face a crisis. The work of art is moving away from its essence and becomes a source of "one-time" reading, entertainment and sensual pleasure, as K. Yuldashev says. G. Binva raises the urgent question of what criteria should be used to evaluate such works.Answering the question, M. Weller said, "Either we must recognize the ancient dimensions of the ancient high and low genres, or everything must be measured by those laws." So, "low" genres cannot be measured by the criteria of "high" genres. "Expresses his point of view. In our opinion, this is exactly one of the methodological issues.

G.Binova points out that in European and Russian novels postmodernism, neomythological, philosophicalerotic, historical-philological, subjective-mythological, "spiritual utopia" novels are emerging. In some novels, he thinks of postmodernist forms based on movies, music videos, and the globalized world news montage. But his latest conclusion is that the emergence of such novel forms is characteristic of today's globalized era and the world that has become a market for intellectual games, information, events. What form the novel takes is in keeping with the nature of a vast social process that cannot be prevented from being marketed. It cannot be stopped artificially. Such hybridized novel forms can also benefit a reader with a high level of literature and intellect. Only such works should be written by talented writers, "masters of words".

Indeed, the process of modification that emerges through the hybridization of different genres, genre components, styles, images is becoming characteristic of modern literature. This situation has entered Uzbek literature since the 1990s. The law of fiction, the process of modification based on tradition, was accelerated by the end of the twentieth century. "Folk composition" in the novels of U. Hashimov ("Lifes in a dream"), a combination of philosophical-realism and cruel realism in the works of Sh. Kholmirzaev ("Dinosaur"), a combination of philosophical, scientific, narrative-mythological and artistic composition and style in the novels of O. Mukhtor ("Plato", "A Thousand and One Images", "Women's Kingdom and Country", etc.), philosophical polyphony in the novel by M.Muhammad Dost ("Lolazor"), the harmony of folklore-folk individual-social style in the novels of T.Murod (" The fields left by my father ", "You can't die in this world ", G.Marquez neorealism in N.Eshonkul's novel and Kafka's modernism ("Gorogly "), Ulysses's chaotic way of thinking in T.Rustamov's novel ("Game of butterflies ") This is evidenced by the socio-philosophical, individual-psychological spirit found in the novels of U. Hamdam, and finally the hybrid of postmodernist composition, plot and images in the novels of I. Sultan ("Eternal Wanderer", "Free", "Genetic"). These facts only require the study of I.Sultan's novels on the problem of artistic modification of many lyrical, dramatic, especially prose genres that saw the world after independence.

Hence, artistic modification is one of the broadest aesthetic phenomena. It stems primarily from literary influences and an aesthetic approach to tradition. The period and the fact that the traditional forms of this period change according to the needs of the reader show the legitimacy of artistic modification. Another reason for the phenomenon of modification is the change of aesthetic criteria in the literary process, the beginning of a different approach to literature by creators. In this case, each artistic component or the whole literary genre itself, which has undergone a change of form, occurs as an aesthetic sign of the author's creative individuality. Although it is rare in 
the process of modification to combine several artistic components (composition, plot, image, detail, style, etc.) into a single work, this aesthetic phenomenon ultimately leads to genre modification.

\section{References}

Poetic dictionary of Kvyatkovskogo. - Michurinsk: Michurinskiy gosudarstvennyy agrarnyy universitet, 2006. $197 \mathrm{p}$.

Philosophical dictionary. - Moscow: Politizdat, 1987. - p. 290.

Alekseeva M.A. Modification of poetic mythology of the XIX century in the work of B. Pasternak in the 1910s. Specified source. - S. 13.

FGBOU VPO «Kabardino-Balkar State University im. H.M.Berbekova », Nalchik, Russia

(360004, Nalchik, ul. Chernyshevskogo, 173), e-mail: assbora@mail.r

Borova A.R. Modification of the image: poetry A.Keshekova 1960-x gg. / FGBOU VPO «Kabardino-Balkar State University im. X.M.Berbekova », Nalchik, Russia, e-mail: assbora@mail.ru

Aleksandrov N. "Ya leplyu iz plastilina” // Notes on modern story. Drujba narodov №9, 1995. - C. 130.

Binova G. Genre modifications of new Russian prose / www.gramota.net/materials. 2401.

Kurchatkin A. Forward to the detective and thriller // Literaturnaya gazeta. - №12, 1993.

Comrade Q., Comrade M. Fundamentals of artistic analysis. - Tashkent: Kamalak, 2016. - B. 415-416. www.gramota.net/materials.

www.gramota.net/materials/2/2014/12-3/8.html 